\title{
DESKRIPSI SUMBERDAYA PERIKANAN DESA TUMBAK MADANI KABUPATEN MINAHASA TENGGARA ${ }^{1}$
}

\author{
Description of Fisheries Resources at Tumbak Madani Village, \\ District Minahasa Tenggara
}

\author{
Hartarto Sormin ${ }^{2}$, Djuwita RR Aling ${ }^{3}$, Olvie V Kotambunan ${ }^{3}$
}

\begin{abstract}
This research is conducted to identify any potential resources in Tumbak Madani village, Pusomaen district, Minahasa Tenggara, North Sulawesi province. The methodology is using several case studies that are acquired by conducting an intensive close contact research with the people. The population of Tumbak Madani village is 512 people and consists of 249 females and 263 males. There are 109 people who received education and most of the villagers are fishermen about 130 people. As an Islamic village, Tumbak Madani has an Islamic social interaction and culture such as social stratification, ritual for new born baby and other cultural law. There are two social groups within the people that are women Islamic group and fishermen group. Coral reef area is the main economic resource for the people in Tumbak Madani village. The area is the habitat for 7 mangrove types and 53 fish family that divided into fish for consumption and fish for ornamental. Tourism and marine fish farming seem to be the next economic opportunity to explore all of Tumbak Madani resources.
\end{abstract}

Keywords : Tumbak Madani, potency, fishery resources, culture

\section{ABSTRAK}

penelitian ini untuk mengetahui dan mengungkapkan apa saja potensi desa Tumbak Madani Kecamatan Pusomaen, Kabupaten Minahasa Tenggara, Provinsi Sulawesi Utara. Dasar penelitian yang digunakan studi kasus, yaitu salah satu tipe pendekatan dalam penelitian yang dilakukan secara intensif, mendalam, mendetail, dan komprehensif. Potensi Sumberdaya Manusia yang dimiliki oleh desa terdiri dari 512 jiwa, 249 wanita dan 263 pria, masyarakat desa paling banyak bermata pencaharian sebagai nelayan sebanyak 130 orang, agama yang mereka anut $100 \%$ beragama islam. Ada 2 Kelompok sosial di desa, kelompok pengajian ibu-ibu dan kelompok karya nelayan bagi pria. Potensi Sumberdaya Perikanan yang dimiliki oleh desa meliputi terumbu karang yang berguna bagi desa yang berfungsi menghasilkan perekonomian bagi masyarakat desa dalam berperan penting dalam melestarikan ikan konsumsi dan ikan hias terdapat 53 family ikan yang ada di desa sehingga berpotensi untuk budidaya ikan air laut, selain terumbu karang desa Tumbak Madani juga memiliki 7 spesies tumbuhan mangrove, yang telah dimanfaatkan untuk membuat pagar dan juga kayu api untuk memasak dan juga berpotensi sebagai potensi pariwisata.

Kata kunci : Tumbak Madani, potensi, sumberdaya perikanan, budaya

\footnotetext{
Bagian dari skripsi

2 Mahasiswa Program Studi Agrobisnis Perikanan FPIK-UNSRAT

${ }^{3}$ Staf pengajar Fakultas Perikanan dan IImu Kelautan Universitas Sam Ratulangi
} 


\section{PENDAHULUAN}

Tingginya keanekaragaman hayati di wilayah pesisir dan lautan Indonesia merupakan harta yang sangat berharga untuk menunjang kehidupan manusia. Kekayaan dan keindahan wilayah laut dan pesisir dapat dimanfaatkan sebagai sumberdaya yang amat penting untuk perikanan dan pariwisata. Berpuluh juta orang khususnya nelayan, menggantungkan hidupnya dari sumberdaya laut dan pesisir (Puspitaningasih, 2012). Potensi sumberdaya di Sulawesi Utara yang kaya potensi sumberdaya pesisir dan lautan dapat memberikan kesempatan untuk berkembang usaha perikanan maupun pariwisata didaerah ini. Keadaan laut di Desa Tumbak Madani juga berperan besar dalam sektor perikanan dan juga sektor pariwisata yang belum termanfaatkan secara maksimal. Ada beberapa jenis sumberdaya bernilai ekonomis penting yang telah dimanfaatkan oleh masyarakat nelayan di kawasan pesisir dan pulau-pulau kecil seperti kayu bakau, moluska, terumbu karang dan ikan. Peralatan penangkapan ikan yang digunakan oleh sebagian besar nelayan di Desa Tumbak Madani masih bersifat tradisional, seperti jaring dan alat penangkapan ikan lainnya, dilengkapi dengan sarana penangkapan seperti perahu/kapal motor. Desa Tumbak Madani memiliki pulau-pulau kecil yang dapat langsung terlihat dari desa, mempunyai karakteristik spesifik, terisolasi dan mempunyai lingkungan yang khusus dengan proporsi spesies ikan yang tinggi serta sosial budaya yang spesifik pula. Oleh karena itu diperlukan penelitian-penelitian yang dapat mengungkapkan potensi tersebut di Desa Tumbak Madani.

Dari uraian di atas menunjukan bahwa penelitian terhadap potensi sumberdaya perikanan di Desa Tumbak Madani penting untuk dilaksanakan dalam rangka mengetahui dan mengembangkan potensi yang ada yang pada akhirnya untuk menaikkan taraf hidup nelayan. Hal inilah yang menyebabkan daerah ini dipilih sebagai lokasi penelitian.

\section{METODE}

\section{a. Lokasi dan waktu penelitian}

Pengambilan data dilakukan di Desa Tumbak Madani pada posisi geografis $00^{\circ} 58^{\prime} 21,6^{\prime \prime}$ LU dan $124^{\circ} 53^{\prime}$ 00,3 " BT (Gambar 1). Pengambilan data diambil pada bulan Juli 2012.

\section{b. Sifat dan dasar penelitian, metode pengambilan sampel \\ Penelitian ini bersifat deskriptif} yaitu untuk eksplorasi dan klarifikasi mengenai suatu fenomena atau kenyataan sosial dengan jalan mendeskripsikan sejumlah variabel yang berhubungan dengan masalah dan unit yang diteliti (Faisal, 1995).

Dasar penelitian yang digunakan adalah studi kasus, yaitu salah satu tipe pendekatan dalam penelitian yang dilakukan secara intensif, mendalam, mendetail, dan komprehensif.

Pengambilan data menggunakan metode purposive random sampling, yaitu jika dari populasi hanya diambil subyek-subyek tertentu yang memenuhi ciri-ciri dan sudah ditentukan terlebih dahulu karena dianggap sudah mewakili populasi (Sigit, 1999). Di desa Tumbak Madani tercatat ada 130 orang nelayan merupakan populasi dalam penelitian ini, diambil $25 \%$ yaitu 32 orang yang meliputi 10 orang nelayan jubi, 10 orang nelayan pancing hand line, 10 orang nelayan yang merupakan tokoh agama dan tokoh budaya, dan 2 orang yang bertugas di kelurahan yaitu lurah dan sekretaris kelurahan.

Data sekunder diambil dari laporan statistik yang ada pada lembaga pemerintah setempat dan LSM yang meliputi letak dan luas desa, jumlah penduduk, tingkat pendidikan, mata pencaharian masyarakat, agama, keadaan umum perikanan dan terumbu karang (karang yang sudah rusak dan yang masih baik), ikan-ikan yang biasanya ditangkap (ikan hias maupun 
ikan konsumsi), serta penyebaran dan jenis-jenis tumbuhan bakau yang ada.

\section{c. Analisa data}

Data yang dikumpulkan, selanjutnya dianalisis berdasarkan analisis deskriptif kualitatif dan analisis deskriptif kuantitatif. Analisis deskriptif kualitatif yaitu dengan memberikan gambaran serta keterangan dengan menggunakan kalimat penulis sendiri sesuai dengan data yang diperoleh. Sedangkan analisis deskriptif kuantitatif yakni dengan menggunakan dan melakukan sejumlah perhitungan matematika sederhana.

\section{HASIL DAN PEMBAHASAN}

\section{a. Gambaran Umum Lokasi}

Desa Tumbak Madani terletak di Kabupaten Minahasa Tenggara, yang berjarak kira-kira 100 km dari Manado. Desa ini termasuk dalam Kecamatan Pusomaen. Desa tetangga terdekat adalah desa Tatengesan $3,5 \mathrm{~km}$ ke arah Barat dan desa Bentenan $3 \mathrm{~km}$ ke arah Utara. Desa Tumbak dimekarkan menjadi dua desa pada bulan April 2010. Dua desa itu adalah desa Tumbak Madani dan desa Tumbak Induk.

\section{b. Sejarah Desa Tumbak Madani}

Penduduk yang mula-mula mendiami Desa Tumbak berasal dari Tilamuta Gorontalo, yang terdiri dari suku Bugis, suku Bajo dan suku Gorontalo. Penduduk pada awalnya terdiri dari 11 rumah tangga yang di kepalai oleh Dotu Saban I Mau dan pembantunya A.S Bachdlar yang datang sekitar tahun 1881. Tujuan mereka datang ke desa ini adalah mencari hasil laut seperti kerang, teripang, ikan laut dan lain-lain. Konon diceritakan bahwa salah satu anggota rombongan, yaitu Dotu Saban I menderita sakit sehingga mereka yang seharusnya singgah dibeberapa tempat seperti daerah Bolaang Mongondow tidak terlaksana, kemudian mereka memutuskan untuk singgah disebelah timur Belang atas ijin Hukum Besar Ratahan untuk berobat. Dalam waktu yang tidak lama, Dotu Saban I sembuh dari sakitnya. Bertepatan pada waktu itu, di tempat yang sama sering terjadi pembunuhan dan perampokan oleh orang-orang Loloda. Akan tetapi kedatangan rombongan ternyata disegani, sehingga, tidak pernah lagi terjadi pembunuhan dan perampokan. Oleh sebab itu mereka tidak dibiarkan pergi untuk meneruskan perjalannya oleh pemerintah Ratahan, dan memperoleh wilayah tempat tinggal yang sekarang dikenal sebagai Desa Tumbak yang berdiri sekitar tahun 1918 .

\section{c. Letak dan Batas Desa}

Berada pada titik. $00^{\circ} 58^{\prime} 21,6$ " LU dan $124^{\circ} 53^{\prime} 00,3^{\prime \prime}$ BT. Batas-batas Desa Tumbak Madani adalah :

- Sebelah Utara berbatasan dengan Desa Tumbak Induk, Desa Bentenan

Sebelah Selatan berbatasan dengan Desa Minanga

- Sebelah Timur berbatasan dengan Laut Maluku

- Sebelah Barat berbatasan dengan Desa Tatengesan

\section{d. Potensi Sumberdaya Manusia}

Penduduk Desa Tumbak Madani berjumlah $149 \mathrm{KK}$, dengan jumlah jiwa sebesar 512 jiwa yang terdiri dari wanita 249 jiwa dan pria 263 jiwa.

Tabel 1. Tingkat Pendidikan

\begin{tabular}{|c|c|c|c|}
\hline No & $\begin{array}{c}\text { Tingkat } \\
\text { Pendidikan }\end{array}$ & $\begin{array}{c}\text { Jumlah } \\
\text { (Jiwa) }\end{array}$ & $\begin{array}{c}\text { Persentase } \\
(\%)\end{array}$ \\
\hline 1. & Tidak sekolah & 403 & $78,71 \%$ \\
\hline 2. & Tamat SD & 68 & $13,28 \%$ \\
\hline 3. & Tamat SLTP & 25 & $4,88 \%$ \\
\hline 4. & Tamat SMU & 15 & $2,92 \%$ \\
\hline 5. & Tamat PT & 1 & $0,19 \%$ \\
\hline \multicolumn{2}{|c|}{ Jumlah } & 512 & $100 \%$ \\
\hline
\end{tabular}

Pendidikan merupakan salah satu kebutuhan yang sangat penting bagi masyarakat terutama bagi masyarakat nelayan. Melalui pendidikan masyarakat nelayan dapat berpikir maju da- 
lam memperhatikan lingkungan hidup maupun lingkungan perairan di desa

Penduduk Desa Tumbak Madani memiliki mata pencaharian yang beragam, masing-masing memiliki keahlian dan ketrampilan yang berbeda. Namun, sebagai masyarakat yang hidup dan bermukim didaerah pantai, maka pekerjaan sebagai nelayan mempunyai persentase yang lebih tinggi dibandingkan dengan mata pencaharian lain.

Tabel 2. Mata Pencaharian

\begin{tabular}{|c|l|c|c|}
\hline No & $\begin{array}{c}\text { Jenis Mata } \\
\text { Pencaharian }\end{array}$ & $\begin{array}{c}\text { Jumlah } \\
\text { (orang) }\end{array}$ & $\begin{array}{c}\text { Persentase } \\
(\%)\end{array}$ \\
\hline 1. & Nelayan & 130 & $87,24 \%$ \\
\hline 2. & Petani & 2 & $1,34 \%$ \\
\hline 3. & PNS & 3 & $2,01 \%$ \\
\hline 4. & Swasta & 5 & $3,35 \%$ \\
\hline 5. & $\begin{array}{l}\text { Pengumpul } \\
\text { ikan }\end{array}$ & 1 & $0,67 \%$ \\
\hline 6. & Tukang & 4 & $2,68 \%$ \\
\hline 7. & Sopir & 4 & $2,68 \%$ \\
\hline & Jumlah & 149 & $100 \%$ \\
\hline
\end{tabular}

\section{e. Potensi Budaya}

Penduduk Desa Tumbak Madani tercatat $100 \%$ memeluk agama Islam. Budaya yang berlaku di masyarakat seperti masyarakat Tumbak Madani mempercayai katula yaitu kemalangan, keruntuhan atau yang disebabkan oleh kutuk karena perbuatan yang kurang baik terhadap orang tua atau karena perbuatan yang melanggar larangan. Seorang Bajo yang katula percaya bahwa bila hasil tangkapan ikannya tidak baik, kehidupan cintanya gagal, kehidupannya yang miskin, terjadi karena melakukan perbuatan yang dilarang dalam kehidupan masyarakat Bajo.

Orang Tumbak Madani terutama bagi orang Bajo, mempunyai kebiasaan menyalakan lampu ketika malam tiba. kalau sumbu lampu sudah dinyalakan atau lampu listrik, akan membuat mereka tenang. Bagi mereka cahaya merupakan tanda adanya orang dalam rumah. Budaya yang lain adalah pada saat salah satu warga Desa Tumbak Madani melahirkan, orang tersebut akan melakukan ritual-ritual adat kepada bayi yang dilahirkan. Ritual dipimpin oleh sandro (sebutan bagi pemimpin ritual). Satu minggu setelah lahir di pagi hari bayi akan menjalani ritual bantang dan ketika malam dilakukan buang kaka (buang plasenta/ari-ari) dikubur di depan atau belakang rumah, dengan mengubur di depan rumah, dianggap kakak dari bayi tersebut berada di sekitar rumah atau menjadi teman bermain dari bayi tersebut

\section{f. Interaksi Sosial}

Bentuk interaksi sosial yang ada di Desa Tumbak Madani biasanya berupa usaha kerjasama antara individu atau kelompok demi mencapai tujuan bersama, seperti orang yang punya kapal biasanya kerjasama dengan tetangganya atau keluarganya dalam menangkap ikan. Atau juga kerjasama antara nelayan-nelayan terhadap pengumpul ikan.

Adapun bentuk interaksi sosial persaingan terjadi dalam hal penangkapan ikan, kesuksesan keluarga, maupun usaha yang dijalankan oleh masing-masing keluarga. Sebagai contoh, jika satu keluarga mencoba usaha budidaya rumput laut, kemudian keluarga/tetangga yang tidak senang akan menghancurkan usaha tersebut, seperti merusak atau memotong tali pengait rumput laut. Ada juga usaha keramba, jika ada yang tidak menyukai keluarga tersebut, maka keramba itu akan dipotong atau dirusak pada saat malam hari. Hal seperti ini sudah biasa terjadi di Desa Tumbak Madani, tapi karena masyarakat merasa bahwa itu sangat memalukan, maka sekarang sudah jarang terjadi. Pertentangan di Tumbak Madani yang masih sering diributkan adalah batas laut dan batas desa dengan Tumbak Induk. Hal ini merupakan dampak dari pemekaran desa tahun 2010.

\section{g. Stratifikasi Sosial}

Di Desa Tumbak Madani masih ada stratifikasi sosial, walaupun tidak terlihat secara langsung, tetapi tingkah 
laku dan perlakuan-perlakuan terhadap orang tertentu bisa diketahui. Hal tersebut terungkap dari 32 responden $(100 \%)$ yang mengatakan bahwa seperti penghormatan dan keseganan kepada Bachdlar sebagai hukum tua yang merupakan keturunan Dotu Saban I, dan juga orang seorang haji. Mereka dihormati, disegani dan diakui kedudukannya bukan dari ukuran kekayaan. Mereka sangat diperlukan pada saat peringatan desa atau pembuatan mesjid, dan juga pada saat ada perkelahian sesama keluarga atau anak muda, mereka sangat berpengaruh dalam peleraian atau pada saat pendamaian, dan juga merupakan pengontrol kehidupan dalam bermasyarakat. Saat ini yang dianggap stratifikasinya lebih tinggi berjumlah 5 orang, semuanya haji.

\section{h. Kelompok Sosial}

Secara geografis kawasan pesisir terletak pada wilayah transisi antara darat dan laut. Sebagian besar masyarakat yang hidup wilayah tersebut disebut sebagai masyarakat nelayan. Masyarakat nelayan didefinisikan sebagai kesatuan sosial kolektif masyarakat yang hidup dikawasan pesisir dengan mata pencahariannya menangkap ikan di laut (Kusnadi, 2009).

Kelompok sosial atau kesatuan sosial adalah himpunan atau kesatuan manusia yang hidup bersama oleh karena adanya hubungan di antara mereka. Hubungan tersebut menyangkut hubungan timbal balik yang saling mempengaruhi dan juga suatu kesadaran saling menolong (Haryanto dan Nugrohadi, 2011). Kelompok sosial yang ada di Desa Tumbak Madani yaitu pengajian ibu-ibu dan kelompok karya nelayan.

\section{i. Potensi Sumberdaya Terumbu Karang}

Terumbu karang merupakan salah satu ekosistem perairan laut yang memiliki produktivitas primer yang sangat tinggi dan merupakan salah satu ekosistem yang menjadi habitat dan aktivitas berbagai biota laut. Tingginya produktivitas primer di perairan terumbu karang memungkinkan perairan menjadi tempat pemijahan (spawning ground), pengasuhan (nursery ground), pembesaran (rearing ground), dan mencari makan (feeding ground), oleh karena itu produksi hasilhasil perikanan di daerah terumbu karang sangat tinggi (Kordi, 2010).

Luas terumbu karang di Desa Tumbak Madani 25 hektar, dari garis pantai menuju lautan lepas panjangnya mencapai $200 \mathrm{~m}$ kemudian berbentuk landai hingga menuju Pulau BalingBaling dan Pulau Ponteng. Penambangan karang di perairan Desa Tumbak Madani dilakukan tidak setiap hari atau setiap minggu. Penambangan karang hanya dilakukan pada saat ada satu keluarga yang akan membangun rumah. Perairan Desa Tumbak Madani juga mempunyai binatang laut pygmy seahorse yang biasa menjadi daya tarik di Provinsi Papua Barat Kabupaten Raja Ampat dan di Provinsi Sulawesi Utara, Selat Lembeh. Karena kurangnya media atau promosi tentang desa Tumbak Madani sampai saat ini hanya 1 resort yang melakukan trip menyelam di perairan Tumbak Madani dan itu hanya sekali setiap 6 bulan atau 1 tahun. Selain itu Berdasarkan pengamatan fishwatch yang dilakukan oleh acroporis, di Desa Tumbak Madani terdapat 53 family ikan konsumsi dan ikan hias.

\section{Mangrove}

Desa Tumbak Madani memiliki 7 spesies mangrove yaitu Bruguiera gymnorhiza, Rhizophora apiculata, $R$. mucronata, Sonneratia alba, $S$. caseolaris, Nypa fruticans, Xylocarpus granatum.

Sonneratia alba atau nama lokal di Tumbak Madani yaitu pohon tatambu biasanya dimanfaatkan bijinya yang bulat, kemudian kulitnya dibuang, lalu setelah bersih dicukur dengan kayu atau besi ditambah air sedikit sampai jadi larut dan dipakai langsung di wajah. Sedangkan kayunya digunakan 
untuk mebel/pembuatan meja atau kursi. Xylocarpus granatum atau pohon papa biasanya dimanfaatkan untuk kayu bakar, bahan bangunan dan mainan seperti kapal-kapal kecil.

Dalam upaya rehabilitasi ekosistem mangrove yang ada di kawasan hutan, status dan keberadaan lahan tersebut adalah milik Negara. Namun untuk ekosistem mangrove yang diluar kawasan hutan status kepemilikan tanahnya sering tidak jelas dan berpotensi menimbulkan konflik. Lahan mangrove diluar kawasan hutan biasanya berstatus hak milik, hak adat atau hak pengelolaan. Masyarakat Desa Tumbak Madani sendiri tidak pernah melakukan penanaman bibit mangrove secara berkelompok atau dalam bentuk kerja bakti. Sebelum desa mengalami pemekaran atau masih bernama Desa Tumbak, pada tahun 2008 program rehabilitasi dari pemerintah masih ada, seiring dengan berjalannya waktu program tersebut tidak terlihat aktivitasnya lagi. Pada tahun 2009 mahasiswa angkatan 2008 Fakultas Perikanan dan IImu Kelautan Universitas Sam Ratulangi melakukan tanam bibit mangrove. Kegiatan seperti ini sekaligus memberikan informasi lingkungan yang diharapkan dapat meningkatkan pengetahuan terhadap anak-anak sekolah dasar Desa Tumbak Madani dan Desa Tumbak Induk dalam mencintai alam dan memeberikan pemahaman bahwa kawasan mangrove yang tumbuh dengan baik dapat menjadi tempat penelitian, kunjungan sekolah dan kegiatan ilmiah lainnya bahkan dapat dijadikan sebagai tempat ekowisata.

\section{j. Potensi Budidaya}

Potensi lahan untuk budidaya air payau di Desa Tumbak Madani cukup besar, khususnya tambak untuk usaha budidaya udang dan bandeng. Akan tetapi hingga saat ini belum ada usaha ke arah tersebut. Untuk itu diperlukan usaha penyuluhan, pendampingan dan pelatihan dari instansi terkait khususnya Dinas Kelautan Perikanan dan
Kelautan terhadap masyarakat. Selain itu, Desa Tumbak Madani merupakan desa yang langsung berhadapan dengan laut dan sejajar dengan garis pantai. Menjadikan desa ini berpotensi untuk kegiatan budidaya air laut seperti budidaya rumput laut, tiram dan budidaya ikan dalam keramba (net impoundment).

Dalam kegiatan budidaya perikanan, pengaruh utama yang perlu diperhatikan antara lain pengaruh yang berasal dari lingkungan sekitar lokasi budidaya termasuk aktivitas di lahan atas, dan pengaruh kegiatan budidaya terhadap lingkungan. Pada tahun 1990an masyarakat Tumbak Madani sudah pernah melakukan usaha budidaya rumput laut Eucheuma sp tetapi sekarang sudah tidak ada, alasannya yaitu persaingan yang ada di masyarakat. Dalam pengembangan budidaya perikanan laut (mariculture), masyarakat juga perlu dilatih dalam ketrampilan untuk membuat rumpon, terumbu karang buatan dan keramba apung untuk melestarikan sumberdaya desa itu sendiri.

Desa Tumbak Madani sendiri sangat berpotensi untuk pembudidayaan ikan keramba dan budidaya tiram mengingat perairan laut didesa cocok sangat ideal untuk melakukan usaha budidaya ikan keramba dan tiram. Ikan keramba di desa biasanya hanya dimiliki oleh orang-orang yang berekonomi baik, sehingga sangat baik jika program PEMP (Progam Pemberdayaan Ekonomi Masyarakat Pesisir) dari pemerintah pusat masuk ke Desa Tumbak Madani karena akan sangat membantu kepada para nelayan yang berekomomian lemah. Untuk budidaya tiram belum pernah dilakukan karena membutuhkan modal yang besar.

Untuk itu konsep Integrated Coastal Zone Planning and Management (ICZPM) atau disebut juga Perancanaan Pengelolaan Wilayah Pesisir Terpadu (PPWPT) perlu dilakukan. 


\section{KESIMPULAN}

Dari hasil penelitian yang dilakukan di Desa Tumbak Madani maka diperoleh kesimpulan:

- Potensi sumberdaya manusia cukup besar, didominasi oleh anak-anak 611 tahun, dengan tingkat pendidikan masyarakat desa masih rendah. paling banyak bermata pencaharian sebagai nelayan, dan $100 \%$ beragama Islam.

- Potensi sosial budaya dapat dilihat dengan masih adanya ritual-ritual, stratifiksi sosial dan adanya 2 kelompok sosial yaitu kelompok pengajian ibu-ibu dan kelompok karya nelayan bagi pria.

- Potensi sumberdaya perikanan yang dimiliki oleh desa meliputi terumbu karang, mangrove dan lamun yang memiliki fungsi ekonomi dan ekologi bagi masyarakat desa.
DAFTAR PUSTAKA

Faisal, S. 1995. Format-Format Penelitian Sosial. PT. Radja Grafindo Persada, Jakarta

Haryanto, D. dan E. Nugrohadi. 2011. Pengantar Sosiologi Dasar. PT. Prestasi Pustaka Raya.Jakarta

Kordi, G. 2010. Ekositem Terumbu Karang. Rineka Cipta. Jakarta

Kusnadi. 2009. Keberdayaan Nelayan dan Dinamika Ekonomi Pesisir. Penerbit Ar-Ruzz Media, Yogyakarta

Puspitaningasih. 2012. Mengenal Ekosistem Laut dan Pesisir. Pustaka Sains. Bogor

Sigit, S. 1999. Pengantar Metodologi Penelitian (Sosial-Bisnis-Manajemen). Digunakan untuk Kalangan Sendiri.

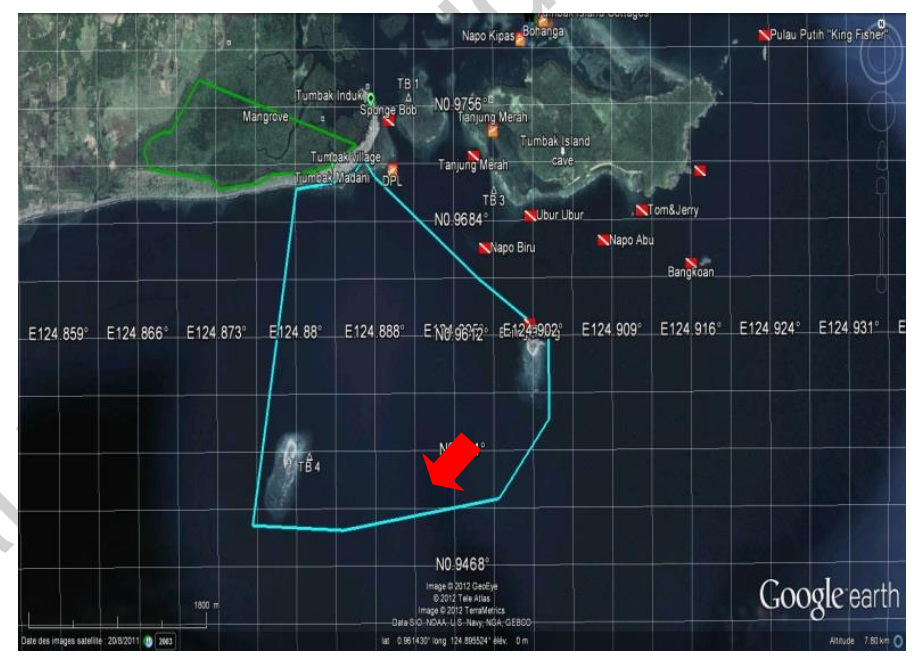

Gambar 1. Lokasi Penelitian Desa Tumbak Madani 